\title{
High CTHRC1 expression may be closely associated with angiogenesis and indicates poor prognosis in lung adenocarcinoma patients
}

Yangshan Chen ${ }^{1 \dagger}$, Yu Sun ${ }^{1 \dagger}$, Yongmei Cui ${ }^{1}$, Yiyan Lei ${ }^{2}$, Neng Jiang ${ }^{1}$, Wenting Jiang ${ }^{1}$, Han Wang ${ }^{1}$, Lili Chen ${ }^{1}$, Jiping Luo ${ }^{1}$, Yanyang Chen ${ }^{1}$, Kejing Tang ${ }^{3}$, Chengzhi Zhou ${ }^{4^{*}}$ and Zunfu Ke $\mathrm{K}^{1,5^{*}}$

\begin{abstract}
Background: This study aimed to investigate the prognostic value of the potential biomarker collagen triple helix repeat containing 1 (CTHRC1) in lung adenocarcinoma (LUAD) patients.

Methods: A total of 210 LUAD patients diagnosed between 2003 and 2016 in the Department of Pathology of the First Affiliated Hospital of Sun Yat-sen University were included in this study. The expression of CTHRC1 and vascular endothelial growth factor (VEGF), and microvessel density (MVD, determined by CD34 immunostaining) were evaluated by immunohistochemistry in LUAD tissues. The association between the expression of these proteins and clinicopathological features or clinical outcomes was analyzed.

Results: Here, we confirmed that CTHRC1 expression was associated with prognosis and can serve as a significant predictor for overall survival (OS) and progression-free survival (PFS) in LUAD. Additionally, we observed that CTHRC1 expression was positively associated with tumor angiogenesis markers, such as VEGF expression $(P<0.001)$ and MVD $(P<0.01)$. Then, we performed gene set enrichment analysis $(G E S A)$ and cell experiments to confirm that enhanced CTHRC1 expression can promote VEGF levels. Based on and cox regression analysis, a predictive model that included CTHRC1, VEGF and MVD was constructed and confirmed as a more accurate independent predictor for OS $(P=0.001)$ and PFS $(P<0.001)$ in LUAD than other parameters.
\end{abstract}

Conclusions: These results demonstrated that high CTHRC1 expression may be closely related to tumor angiogenesis and poor prognosis in LUAD. The predictive model based on the CTHRC1 level and tumor angiogenesis markers can be used to predict LUAD patient prognosis more accurately.

Keywords: Lung adenocarcinoma (LUAD), Collagen triple helix repeat containing 1 (CTHRC1), Vascular endothelial growth factor (VEGF), Microvessel density (MVD), Tumor angiogenesis

\footnotetext{
*Correspondence: doctorzcz@163.com; kezunfu@mail.sysu.edu.cn

${ }^{\dagger}$ Yangshan Chen and Yu Sun contributed equally to this work

1 Department of Pathology, The First Affiliated Hospital, Sun Yat-sen

University, No. 58, Zhongshan Second Road, Guangzhou 510080,

Guangdong, People's Republic of China

${ }^{4}$ State Key Laboratory of Respiratory Disease, National Clinical Research

Center for Respiratory Disease, Guangzhou Institute of Respiratory

Health, The First Affiliated Hospital of Guangzhou Medical University,

Guangzhou 510080, Guangdong, People's Republic of China

Full list of author information is available at the end of the article
}

(c) The Author(s) 2019. This article is distributed under the terms of the Creative Commons Attribution 4.0 International License (http://creativecommons.org/licenses/by/4.0/), which permits unrestricted use, distribution, and reproduction in any medium, provided you give appropriate credit to the original author(s) and the source, provide a link to the Creative Commons license, and indicate if changes were made. The Creative Commons Public Domain Dedication waiver (http://creativecommons.org/ publicdomain/zero/1.0/) applies to the data made available in this article, unless otherwise stated. 


\section{Background}

According to the most recently reported global cancer statistics, lung cancer remains the leading cause of cancer-related deaths [1-3] and the mortality rate is $18.4 \%$ [1]. Lung adenocarcinoma (LUAD), the most commonly diagnosed histologic subtype of lung cancer [4], causes more than 500,000 deaths globally each year $[5,6]$. Currently, the adenocarcinoma subtype of NSCLC had more effective responses to recently developed targeted therapies such as pemetrexed, gefitinib, bevaciuzumab, and crizotinib than the non-adenocarcinoma subtype [7-9]. Despite improvements in chemotherapeutic interventions and surgical resection, the prognosis for patients with LUAD remains poor, with a dismal 5-year survival rate of $16 \%$ [3], which is due to the high occurrence of tumor recurrence and distant metastases $[10,11]$. Accordingly, the discovery of effective prognostic and diagnostic biomarkers in early stage will have a significant impact on further improving treatment outcomes in LUAD.

Collagen triple helix repeat containing 1 (CTHRC1) is a chondrocyte-specific, secreted glycoprotein that was originally discovered in a rat model of balloon-injured arteries [12-17]. The overexpression of CTHRC1 is frequently detected in several solid tumors, such as melanoma, breast ductal carcinoma, gastric cancer, hepatocellular carcinoma and colorectal cancer [1822]. According to our previous studies, CTHRC1 overexpression was significantly correlated with metastasis in patients with non-small cell lung cancer (NSCLC) [23]. However, more evidence still needed to determine the prognostic value of CTHRC1 in LUAD, which is the most common subtype of lung cancer.

Angiogenesis, the process in which capillaries sprout from pre-existing vessels, has long been regarded as the principal mechanism of tumor vascularization, throughout cancer occurrence, growth, migration, invasion and distant metastasis in lung cancer [24-26]. Notably, Pyagay et al. [17] found that CTHRC1 expression cannot be detected in normal arteries but is only transiently expressed in injured arteries. Additionally, it was reported that the overexpression of CTHRC1 can significantly promote tumor angiogenesis in pancreatic tumors and gastrointestinal stromal tumors [27, 28]. However, the relationship between CTHRC1 expression and tumor angiogenesis in LUAD remains unclear.

Therefore, in the current study, we aimed to examine the association of CTHRC1 expression and tumor angiogenesis and to provide more significant evidence for its application in LUAD prognosis.

\section{Materials and methods \\ Patients}

A total of 210 LUAD patients were included in this study; patients were diagnosed between 2003 and 2016 in the Department of Pathology of the First Affiliated Hospital of Sun Yat-sen University and followed up for between 6 and 125 months (median 46.0 months). The patients' clinical and tumor pathological characteristics are shown in Table 1. Formalin-fixed and paraffin-embedded (FFPE) cancer surgical specimens were used to perform subsequent analyses. This study was approved by the institutional ethics committee of the First Affiliated Hospital

Table 1 Correlation of CTHRC1 and clinicopathologic characteristics in patients with LUAD

\begin{tabular}{|c|c|c|c|c|}
\hline \multirow{2}{*}{$\begin{array}{l}\text { Clinicopathologic } \\
\text { characteristics }\end{array}$} & \multirow{2}{*}{$\begin{array}{l}\text { All cases } \\
(n=210)\end{array}$} & \multicolumn{2}{|c|}{ CTHRC1 expression } & \multirow[t]{2}{*}{$P$-value } \\
\hline & & $\begin{array}{l}\text { Low } \\
(n=137)\end{array}$ & $\begin{array}{l}\text { High } \\
(n=73)\end{array}$ & \\
\hline \multicolumn{5}{|l|}{ Gender } \\
\hline Male & 114 & 80 & 34 & \multirow[t]{2}{*}{0.111} \\
\hline Female & 96 & 57 & 39 & \\
\hline \multicolumn{5}{|l|}{ Age (years) } \\
\hline$\leq 50$ & 64 & 39 & 25 & \multirow[t]{2}{*}{0.432} \\
\hline$>50$ & 146 & 98 & 48 & \\
\hline \multicolumn{5}{|l|}{ Smoking } \\
\hline Yes & 43 & 33 & 10 & \multirow[t]{2}{*}{0.105} \\
\hline No & 167 & 104 & 63 & \\
\hline \multicolumn{5}{|l|}{ Tumor differentiation } \\
\hline Well & 10 & 7 & 3 & \multirow[t]{3}{*}{0.172} \\
\hline Moderately & 181 & 114 & 67 & \\
\hline Poorly & 19 & 16 & 3 & \\
\hline \multicolumn{5}{|l|}{ Clinical stage } \\
\hline 1 & 130 & 102 & 28 & \multirow[t]{4}{*}{$<0.001$} \\
\hline$\|$ & 25 & 11 & 14 & \\
\hline III & 36 & 18 & 18 & \\
\hline IV & 19 & 6 & 13 & \\
\hline \multicolumn{5}{|l|}{ T classification } \\
\hline $\mathrm{T} 1$ & 76 & 53 & 23 & \multirow[t]{4}{*}{0.025} \\
\hline $\mathrm{T} 2$ & 112 & 76 & 36 & \\
\hline T3 & 12 & 5 & 7 & \\
\hline T4 & 10 & 3 & 7 & \\
\hline \multicolumn{5}{|l|}{ N classification } \\
\hline No & 146 & 107 & 39 & \multirow[t]{4}{*}{0.001} \\
\hline $\mathrm{N} 1$ & 21 & 9 & 12 & \\
\hline N2 & 33 & 18 & 15 & \\
\hline N3 & 10 & 3 & 7 & \\
\hline \multicolumn{5}{|l|}{ M classification } \\
\hline Mo & 195 & 132 & 63 & \multirow[t]{2}{*}{0.011} \\
\hline M1 & 15 & 5 & 10 & \\
\hline
\end{tabular}

Fisher's exact tests; Chi-square tests. Statistical significance $(P<0.05)$ is shown in italic

LUAD lung adenocarcinoma, CTHRC1 collagen triple helix repeat containing 1 , TNM tumor-node-metastasis 
of Sun Yat-sen University, and written informed consent was obtained from all patients.

\section{Immunohistochemistry (IHC)}

Representative paraffin-embedded tissues were arrayed with a tissue-arraying instrument with $2.0-\mathrm{mm}$ diameter core and were sectioned ( $4 \mathrm{um})$ for further analysis. CTHRC1 (Abcam, Cambridge, UK) was used in a 1:100 dilution [29, 30], VEGF (ZSGB-Bio, Beijing, China) and CD34 (ZSGB-Bio, Beijing, China) was used in ready to use dilution [31]. Samples were incubated with antibodies against CTHRC1 (Abcam, Cambridge, UK), VEGF (ZSGB-Bio, Beijing, China) and CD34 (ZSGB-Bio, Beijing, China). The protocol for the IHC staining of tumor tissues from humans was described previously [32]. Brown particles in the cytoplasm represent CTHRC1or VEGF- positive staining. The expression intensities of CTHRC1 and VEGF were semiquantitatively evaluated according to the immunostaining intensity and positive cell distribution. The percentage of positive tumor cells was determined in at least three areas at $400 \times$ magnification and was averaged. The mean percentage was then assigned to one of five categories (Additional file 1: Fig. S1a-j): 0 , no cancer cells stained; $1,0-10 \%$ of cancer cells stained; $2,11-50 \%$ of cancer cells stained; $3,51-75 \%$ of cancer cells stained, 4 , more than $75 \%$ of cancer cells stained. The intensity of immunostaining was scored as follows: 0 , colorless; $1, \tan$; 2, brownish-yellow; and 3, dark brown. A weighted score was obtained by multiplying the positive cell percentage and staining intensity for each case. Microvessel density (MVD) was evaluated by the technique of Weidner et al. [33] and was based on the average CD34 positive cell count from IHC staining. Tumor slides were scanned first at low magnification $(100 \times)$ to select three fields with the highest vascularization where the cell membrane of vascular endothelial cells was present and (or) there was brown staining, and then the microvessels were counted at high magnification $(400 \times)$ (Additional file 1: Fig. S1k-o). Microvessels with a clearly defined lumen or a well-defined linear vessel shape were selected for counting and branching vessel structures were regarded as a single vessel. The mean value of three fields was considered as the microvessel density (MVD) for each case. Based on the receiver operative characteristic (ROC) analysis, the optimal cutoff value of CTHRC1, VEGF and MVD was confirmed: a staining index of 7.5 and 5 or greater was used to define tumors with high CTHRC1 and VEGF expression, respectively, and a staining index below 7.5 or 5 was defined as low expression; an evaluation of 28.5 or greater was used to define tumors with a high MVD, while an evaluation below 28.5 was used to define tumors with a low MVD [23, 34, 35].

\section{Gene set enrichment analysis (GSEA)}

JavaGSEA-3.0 was downloaded from the official website. Before performing the analysis, we downloaded the related Molecular Signatures Database (MSigDB) and obtained microarray data from 40 LUAD patients and from the microarray data of 514 LUAD cases from The Cancer Genome Atlas (TCGA) database (https://www. cbioportal.org/, accessed September 18, 2019). These two cohorts were divided into a high-CTHRC1 group and a low-CTHRC1 group based on the level of CTHRC1 expression. GSEA was then carried out to determine the functions or pathways that showed statistically significant, concordant differences between the two groups. A positive enrichment score (ES) and a normalized enrichment score (NES) indicate that the majority of genes in this gene set were positively associated with our predefined group statuses. A normalized $P$-value (NOM $P$-value) of $<0.05$ was considered statistically significant.

\section{Cell lines}

Primary normal lung epithelial cells (BEAS-2B) were purchased from American Type Culture Collection (ATCC) and cultured in a keratinocyte serum-free medium (Invitrogen, Carlsbad, CA) supplemented with epidermal growth factor (EGF) (Invitrogen), bovine pituitary extract, and antibiotics $(100 \mu \mathrm{g} / \mathrm{mL}$ streptomycin and 100 $\mathrm{U} / \mathrm{mL}$ penicillin). Lung adenocarcinoma cell lines (A549, GLC-82, SPC-A1, PC9, H1299 and H1975) and non-adenocarcinoma cell lines (L78 and H460) were maintained in Dulbecco's modified Eagle's medium (DMEM; Invitrogen, USA) supplemented with $10 \%$ fetal bovine serum (HyClone, San Angelo, TX, USA).

\section{Stable clone establishment}

CTHRC1 shRNA vectors (GV248, CTHRC1-shRNA, and Control shRNA) and CTHRC1-overexpression vectors (GV358, CTHRC1, and Control vector) were purchased from GeneChem (Shanghai, China), and were manipulated according to the protocol provide by the manufacturer. The transfection efficiency of the template was detected by fluorescence microscope (Axio Observer Z1, Zeiss), western blotting and quantitative real-time PCR.

\section{Western blotting (WB)}

Western blotting was performed as previously described [32]. Targeted membranes were incubated with the antibodies for CTHRC1 (Abcam, USA), VEGFA (Abcam, USA) and Actin (Cell Signaling Technology, USA) in 5\% milk/tris-buffered saline Tween-20 (TBST) at $4{ }^{\circ} \mathrm{C}$ overnight, and then were washed with TBST and incubated with horseradish peroxidase (HRP)-conjugated secondary antibodies (Cell Signaling Technology, USA) for $1 \mathrm{~h}$ 
with shaking. After enhanced chemiluminescence (ECL) (Merck Millipore, Germany) reaction, the immunoreactive bands were observed through a Gel Imaging System (Syngene, USA).

\section{Total RNA extraction and Quantitative Real-time PCR (qRT-PCR)}

Total RNA from tissue specimens and cells was extracted with TRIzol method Invitrogen, USA). RNA was reverse transcribed into cDNA using the two-step method with PrimeScript $^{\mathrm{TM}}$ RT reagent kit with gDNA Eraser (Takara, China), according to the manufacturer's instructions. Then, qRT-PCR was performed with the SYBR ${ }^{\circledR}$ Premix Ex TaqTM kit (Takara, China), according to the manufacturer' $s$ protocol. The following primers were used: CTHRC1, forward 5'-TGGACACCCAACTACAAG CA-3' and reverse 5'-GAACAAGTGCCAACCCAG AT-3'; GAPDH, forward 5'-ACCCACTCCTCCACC TTTG- $3^{\prime}$ and reverse $5^{\prime}$-CTCTTGTGCTCTTGCTGG G-3'. GAPDH was used as an internal reference, with the $2^{-\Delta \Delta C t}$ method used for quantitation [36].

\section{Statistical analysis}

Statistical analysis was performed with SPSS 16.0 (SPSS Inc., Chicago, IL, USA). A two-tailed $p$-value of $<0.05$ was considered statistically significant. Bonferroni correction was used to adjust the statistical significance level in multiple testing. Fisher's exact tests, Chi-square tests, a Student's t-test and one-way ANOVA were used for comparisons between groups. The MVD was presented as the mean \pm the standard deviation (SD). The concordance rate of linear regression plots was assessed using the Pearson test. Receiver operative characteristic (ROC) analysis was performed to select the optimal cutoff value and to determine the predictive value of the factors. The Kaplan-Meier method was used to examine the overall survival (OS) and progression-free survival (PFS), and the log-rank test was used to compare curves for two or more groups. To investigate the independent prognostic factors for OS and PFS, a Cox proportional hazard regression model was applied.

\section{Results}

\section{Clinicopathologic patient characteristics}

The clinical and histopathologic characteristics of the 210 LUAD patients are summarized in Table 1 . The patient cohort consisted of $114(54.3 \%)$ males and 96 (45.7\%) females, and the mean age at diagnosis was 58.5 years (range, 33-81 years). Of the 210 patients with a known smoking status, most (79.5\%) were nonsmokers. The tumor size was $2.67 \pm 1.8 \mathrm{~cm}$ (range, $0.4-15 \mathrm{~cm}$ ). Tumors were classified as well, moderately and poorly differentiated for 10 (4.8\%), 181 (86.2\%) and 19 (9.0\%) patients, respectively. The number of patients with pathologic TNM stage I, II, III, and IV was 130 (61.9\%), 25 (11.9\%), $36(17.1 \%)$ and $19(9.0 \%)$, respectively.

\section{Association between CTHRC1 expression and clinicopathologic characteristics in LUAD}

Representative stained fields from histopathological slides for CTHRC1, VEGF and CD34 are displayed in Fig. 1a and Additional file 1: Fig. S1. As shown in Table 1, the CTHRC1 expression status in LUAD was significantly associated with the clinical stage $(P<0.001)$, T classification $(P<0.001)$, N classification $(P<0.001)$ and $M$ classification $(P<0.001)$. In contrast, there were no significant correlations between CTHRC1 expression and other clinicopathologic characteristics.

\section{Association between CTHRC1 expression and patient survival in LUAD}

Univariate analysis of clinicopathologic features demonstrated that age, clinical stage, $\mathrm{T}$ classification, $\mathrm{N}$ classification, $M$ classification and CTHRC1 expression in LUAD were significantly correlated with overall survival (OS) $(P<0.05$; Table 2$)$, while clinical stage, $N$ classification, $M$ classification and CTHRC1 expression in LUAD were significantly correlated with progressionfree survival (PFS) $(P<0.05$; Table 2). According to the Kaplan-Meier analysis, the OS and PFS of patients in the CTHRC1 ${ }^{\text {High }}$ group were significantly shorter than those in the CTHRC $1^{\text {Low }}$ group $(P<0.001$; Fig. 1 b, c). Then, we performed a Kaplan-Meier survival analysis according to clinical stage, $\mathrm{T}$ classification, $\mathrm{N}$ classification and $M$ classification and the data showed that clinical stage, $\mathrm{N}$ classification and $\mathrm{M}$ classification were significantly related to patient survival, and the survival time in the CTHRC1 ${ }^{\text {High }}$ group was distinctly shorter than that in the CTHRC1 ${ }^{\text {Low }}$ group $(P<0.01$; Additional file 1: Fig. S2, Additional file 2: Table S1-S3).

As shown in Table 3, multivariate Cox regression analysis revealed that CTHRC1 expression was an independent prognostic marker for LUAD. The prognostic value of CTHRC1 expression was investigated according to clinical stage, $\mathrm{T}$ classification, $\mathrm{N}$ classification and $M$ classification. Our results showed that the expression of CTHRC1 was strongly associated with the OS and PFS of patients in the clinical stage s I + II, clinical stages III + IV, T1-2, N0 and M0 subgroups $(P<0.05$; Fig. 2$)$. However, no significant difference was observed between the CTHRC $1^{\text {High }}$ group and the CTHRC1 ${ }^{\text {Low }}$ group in the T3-4, N1-3 and M1 subgroups, probably because there was a limited number of samples in these subgroups (Additional file 1: Fig. S3). We concluded that patients with tumors expressing high CTHRC1 levels had distinctly poor 


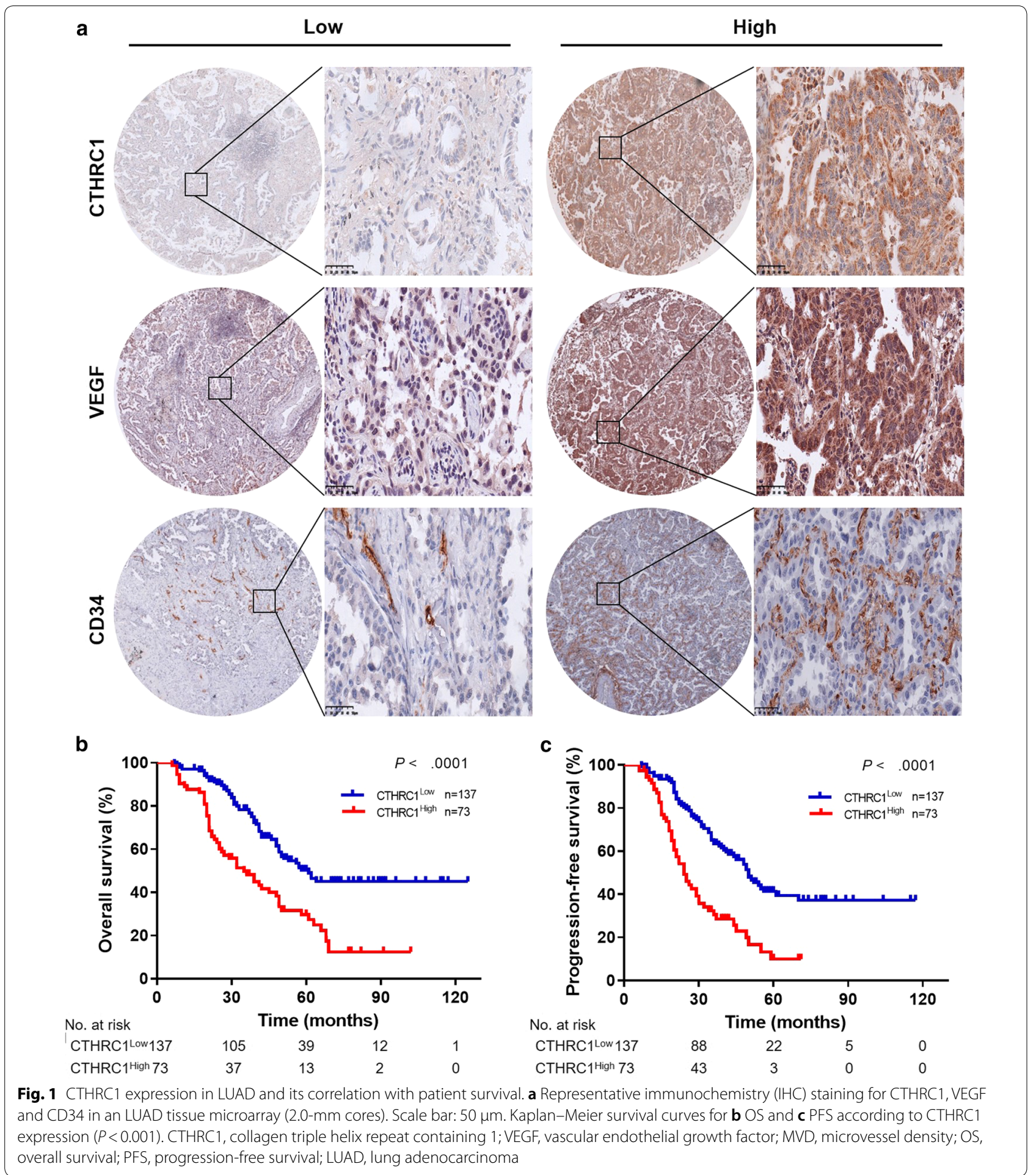

survival compared with patients with low CTHRC1 levels in the early or advanced stage subgroups $(P<0.05$; Fig. 2a, b). Similarly, there was clearly shorter OS and PFS in patients with high CTHRC1 expression in the T1-2 subgroup $(P<0.05$; Fig. 2 c), N0 subgroup
( $P<0.05$; Fig. $2 \mathrm{~d})$ and M0 subgroup $(P<0.05$; Fig. 2 e $)$. Therefore, CTHRC1 may act as an effective prognostic marker for LUAD patients. 
Table 2 Univariate analysis of factors associated with overall survival and progression-free survival in LUAD patients

\begin{tabular}{|c|c|c|c|c|c|c|}
\hline \multirow[t]{2}{*}{ Variables } & \multicolumn{3}{|l|}{ os } & \multicolumn{3}{|l|}{ PFS } \\
\hline & Hazard ratio & $95 \% \mathrm{Cl}$ & $P$-value & Hazard ratio & $95 \% \mathrm{Cl}$ & $P$-value \\
\hline Gender & 1.067 & $0.742-1.534$ & 0.727 & 1.090 & $0.759-1.566$ & 0.640 \\
\hline Age & 1.050 & $1.032-1.069$ & $<0.001$ & 1.504 & $0.993-2.278$ & 0.054 \\
\hline Smoking & 0.990 & $0.637-1.541$ & 0.966 & 0.981 & $0.631-1.525$ & 0.931 \\
\hline Tumor differentiation & 0.724 & $0.450-1.166$ & 0.184 & 0.897 & $0.574-1.400$ & 0.631 \\
\hline Clinical stage & 2.572 & $2.112-3.132$ & $<0.001$ & 2.481 & $2.034-3.025$ & $<0.001$ \\
\hline T classification & 1.414 & $1.106-1.808$ & 0.006 & 1.163 & $0.900-1.504$ & 0.248 \\
\hline N classification & 1.935 & $1.608-2.330$ & $<0.001$ & 1.793 & $1.480-2.172$ & $<0.001$ \\
\hline M classification & 7.165 & $3.673-13.976$ & $<0.001$ & 6.873 & $3.432-13.766$ & $<0.001$ \\
\hline CTHRC1 expression & 2.300 & $1.600-3.308$ & $<0.001$ & 2.643 & $1.827-3.822$ & $<0.001$ \\
\hline VEGF expression & 2.733 & $1.860-4.017$ & $<0.001$ & 3.673 & $2.485-5.429$ & $<0.001$ \\
\hline MVD count & 2.122 & $1.476-3.050$ & $<0.001$ & 1.881 & $1.305-2.711$ & 0.001 \\
\hline
\end{tabular}

$\mathrm{Cl}$ confidence interval; statistical significance $(P<0.05)$ is shown in italic

LUAD lung adenocarcinoma, OS overall survival, PFS progression-free survival, CTHRC1 collagen triple helix repeat containing 1, VEGF vascular endothelial growth factor; MVD microvessel density, TNM tumor-node-metastasis

Table 3 Multivariate analysis of factors associated with overall survival and progression-free survival in LUAD patients

\begin{tabular}{|c|c|c|c|c|c|c|}
\hline \multirow[t]{2}{*}{ Variables } & \multicolumn{3}{|l|}{ os } & \multicolumn{3}{|l|}{ PFS } \\
\hline & Hazard ratio & $95 \% \mathrm{Cl}$ & $P$-value & Hazard ratio & $95 \% \mathrm{Cl}$ & $P$-value \\
\hline Gender & 1.074 & $0.703-1.643$ & 0.740 & 1.204 & $0.790-1.834$ & 0.389 \\
\hline Age & 3.223 & $1.917-5.418$ & $<0.001$ & 2.097 & $1.344-3.273$ & 0.001 \\
\hline Smoking & 0.934 & $0.563-1.588$ & 0.833 & 0.892 & $0.548-1.451$ & 0.644 \\
\hline Tumor differentiation & 0.946 & $0.563-1.588$ & 0.833 & 1.318 & $0.802-2.164$ & 0.276 \\
\hline Clinical stage & 2.996 & $2.135-4.204$ & $<0.001$ & 3.267 & $2.302-4.638$ & $<0.001$ \\
\hline T classification & 0.805 & $0.673-1.016$ & 0.067 & 0.730 & $0.576-0.925$ & 0.009 \\
\hline N classification & 0.911 & $0.665-1.250$ & 0.565 & 0.796 & $0.576-1.100$ & 0.167 \\
\hline M classification & 1.433 & $0.628-3.269$ & 0.393 & 1.163 & $0.504-2.686$ & 0.732 \\
\hline CTHRC1 expression & 1.097 & $1.029-1.170$ & 0.004 & 1.133 & $1.061-1.211$ & $<0.001$ \\
\hline VEGF expression & 0.987 & $0.927-1.051$ & 0.680 & 1.033 & $0.970-1.100$ & 0.313 \\
\hline MVD count & 1.015 & $0.999-1.030$ & 0.060 & 1.005 & $0.990-1.020$ & 0.507 \\
\hline
\end{tabular}

$\mathrm{Cl}$ confidence interval; statistical significance $(P<0.05)$ is shown in italic

LUAD lung adenocarcinoma, OS overall survival, PFS progression-free survival, CTHRC1 collagen triple helix repeat containing 1, VEGF vascular endothelial growth factor, MVD microvessel density, TNM tumor-node-metastasis, $\mathrm{Cl}$ confidence interval

\section{Association between CTHRC1 expression and tumor angiogenesis markers}

We found that patients in the CTHRC1 ${ }^{\text {High }}$ group expressed more VEGF $(P<0.001$; Table 4$)$ and had a higher $\operatorname{MVD}(P=0.001$; Fig. 3a, Table 4$)$ than those in the CTHRC $1^{\text {Low }}$ group. To elucidate the relationship between CTHRC1 expression and tumor angiogenesis, we utilized Gene Set Enrichment Analysis (GSEA) to determine whether a previously defined set of angiogenesis-associated genes showed statistically significant, concordant differences between the high-CTHRC1 group and the low-CTHRC1 group $(\mathrm{ES}=0.556, \mathrm{NES}=1.442 ; P<0.001 ;$ Fig. $3 \mathrm{~b})$ in our microarray data. The results showed that angiogenesisassociated genes were enriched in the high-CTHRC1 group, which indicated that the expression of genes related to the promotion of angiogenesis was more activated in LUAD patients with high CTHRC1 levels than in LUAD patients with low CTHRC1 levels. Additionally, in the TCGA cohort, we observed that the mRNA expression of CTHRC1 was positively associated with the expression of VEGF $(r=0.137, P=0.002$; Fig. 3c), and GSEA also showed that CTHRC1 expression remained linked with angiogenesis $(E S=0.635$, $\mathrm{NES}=1.838$; $P<0.001$; Fig. $3 \mathrm{~d}$ ). As shown in Fig. 3e, CTHRC1 and VEGFA was also differentially increased 


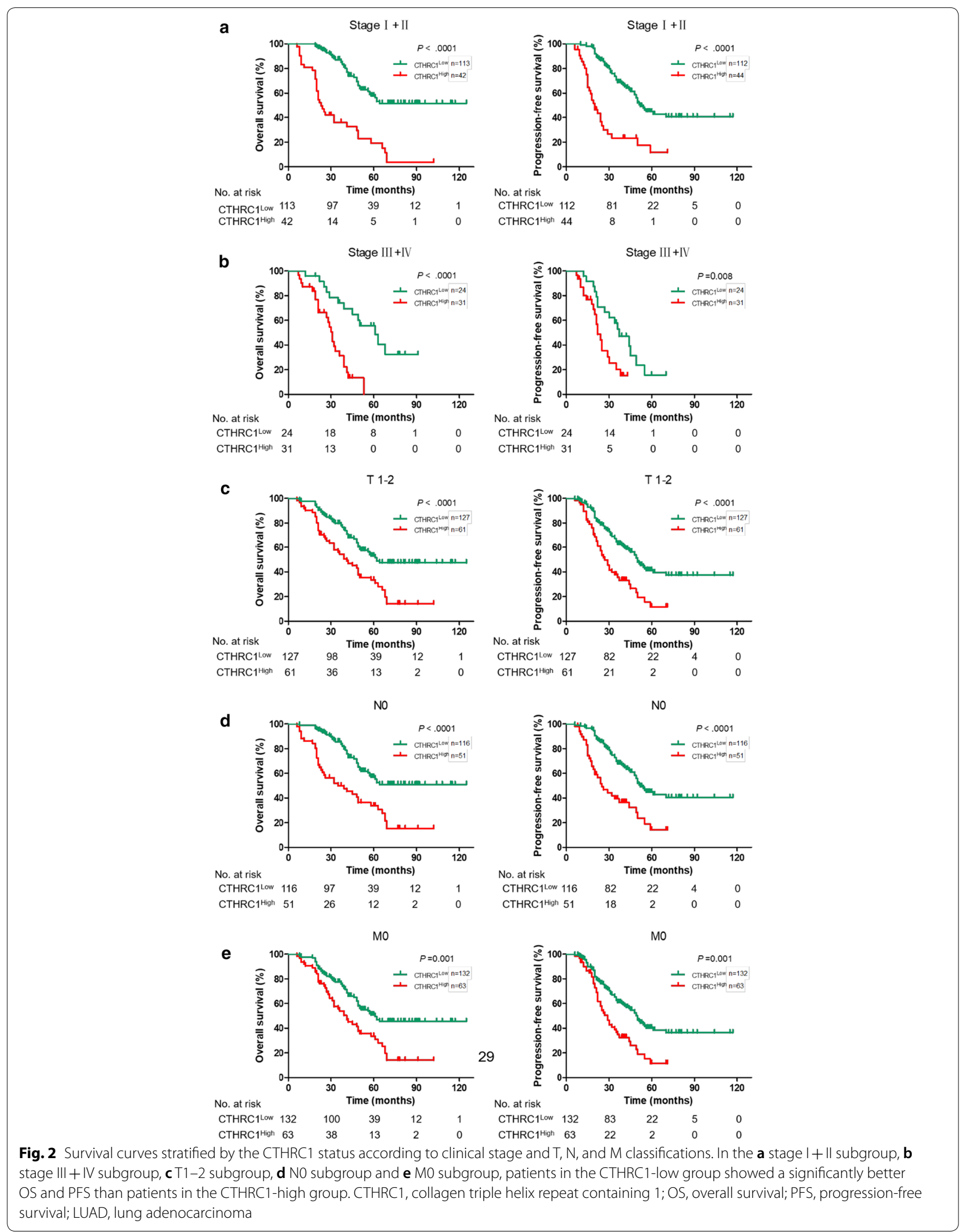


Table 4 Correlation of CTHRC1 expression with VEGF expression and MVD

\begin{tabular}{llll}
\hline Characteristics & \multicolumn{2}{l}{ CTHRC1 expression } & P-value \\
\cline { 2 - 3 } & Low $(\mathbf{n = 1 3 7 )}$ & High $(\mathbf{n = 7 3 )}$ & \\
\hline VEGF expression & & $21(19.8 \%)$ & $<0.001^{\text {a }}$ \\
Low & $85(80.2 \%)$ & $52(50.0 \%)$ & \\
High & $52(50.0 \%)$ & $38(28.4 \%)$ & $0.011^{\text {a }}$ \\
MVD counts & & $35(46.1 \%)$ & \\
Low & $96(71.6 \%)$ & & \\
High & $41(53.9 \%)$ & &
\end{tabular}

CTHRC1 collagen triple helix repeat containing 1, VEGF vascular endothelial growth factor, MVD microvessel density

${ }^{\text {a }}$ Chi-square test, $P<0.05$

in six detected LUAD samples compared to corresponding non-cancerous tissues. These results further demonstrated that high CTHRC1 expression may be closely associated with tumor angiogenesis due to the upregulation of angiogenesis-related genes.

\section{Enhanced CTHRC1 expression can promote VEGF expression in LUAD in vitro}

As shown in Fig. 4a, lung adenocarcinoma cell lines, including A549, GLC-82, SPC-A1, PC9, H1299 and H1975, exhibited higher CTHRC1 levels compared to that of primary human normal lung epithelial cells (BEAS-2B) and non-adenocarcinoma cell lines (L78 and H460). To investigate the angiogenesis marker expression on CTHRC1 enhancement or deregulation LUAD cells, we constructed stable clone of H1299shCTHRC1 cells and A549-CTHRC1 cells by using lentivirus transfection. At $72 \mathrm{~h}$ after transfection with Lv-shCTHRC1 or Lv-CTHRC1 and their corresponding control virus, respectively, H1299 and A549 were observed by fluorescence microscopy. Green fluorescent protein (GFP) was expressed by more than $80 \%$ of the cells (Fig. 4b). After stable transfection and puromycin screening, CTHRC1 mRNA expression and protein levels in the H1299-Lv-shCTHRC1 group were significantly lower than that in the control group $(0.147 \pm 0.015$ versus $1.066 \pm 0.061, P<0.001$; Fig. 4 b, c), while CTHRC1 mRNA expression and protein levels in the A549-Lv-CTHRC1 group were significantly higher than that in the control group (132.6 \pm 7.540 versus $1.035 \pm 0.039, P<0.001$; Fig. $4 b, c)$. Furthermore, the protein levels of VEGFA also presented significantly higher in the A549-Lv-CTHRC1 group than in the control group (Fig. 4c). These data demonstrated that enhanced CTHRC1 expression can promote VEGF expression in LUAD in vitro.
Combining CTHRC1 expression with tumor angiogenesis markers to construct a predictive model

Univariate analysis of clinicopathologic characteristics demonstrated that tumor angiogenesis markers (VEGF and MVD) were significantly associated with OS $(P<0.05$; Table 2$)$ and PFS $(P<0.05$; Table 2$)$. Based on our results described above, it is reasonable to simultaneously consider CTHRC1 expression and tumor angiogenesis markers as a predicted panel. Therefore, we established a predictive model that included CTHRC1, VEGF and MVD, and all patients were divided into three groups: patients were assigned to the low-risk group if the three biomarkers were low; to the moderate-risk group if more than one of the three biomarkers was high; and to the high-risk group if the three biomarkers were high.

\section{CTHRC1 expression concomitant with VEGF expression and MVD predicts prognosis in LUAD}

According to the Kaplan-Meier survival analysis, the three survival curves were significantly different, and high-risk patients had a shorter OS and PFS than those in the low-risk group and moderate-risk group $(P<0.001$; Fig. 5a, Additional file 2: Table S4). Similarly, in multivariable analysis, the predictive model was also confirmed as an independent predictor of OS and PFS $(P<0.05$; Table 5). The predictive power for OS of the predictive model was better, with an area under the curve (AUC) of 0.740 (95\% confidence interval [CI] 0.672-0.808; $P<0.001$; Fig. 5b, c, Additional file 2: Table S5), than other single biomarkers, such as age, clinical stage, $\mathrm{T}$ classification, $\mathrm{N}$ classification, $\mathrm{M}$ classification, CTHRC1, VEGF and MVD, as shown by the ROC analysis. For PFS, although the predictive power of VEGF was the best, with an AUC of 0.704 (95\% CI 0.632-0.776; $P<0.01$; Fig. 5b, c, Additional file 2: Table S5), VEGF was not an independent predictor of prognosis $(P>0.05$; Table 3$)$. Therefore, as an effective predictor for PFS $(P<0.001$; Table 5) in LUAD, the predictive model had the best predictive value, with an AUC of 0.691 (95\% CI 0.620-0.763; $P<0.001$; Fig. 5b, c, Additional file 2: Table S5).

\section{Discussion}

Since CTHRC1 was first identified in a screen for differentially expressed genes in balloon-injured rats [17], an increasing number of scientists have investigated the prognostic value of CTHRC1 in tumors. Liu et al. [37] found that patients with higher CTHRC1 expression exhibited a remarkably shorter OS in four different pancreatic ductal adenocarcinoma (PDAC) cohorts. Additionally, some reports have demonstrated that patients with higher CTHRC1 levels tend to have poor prognosis in many tumors, such as Wilm's tumor, esophageal 

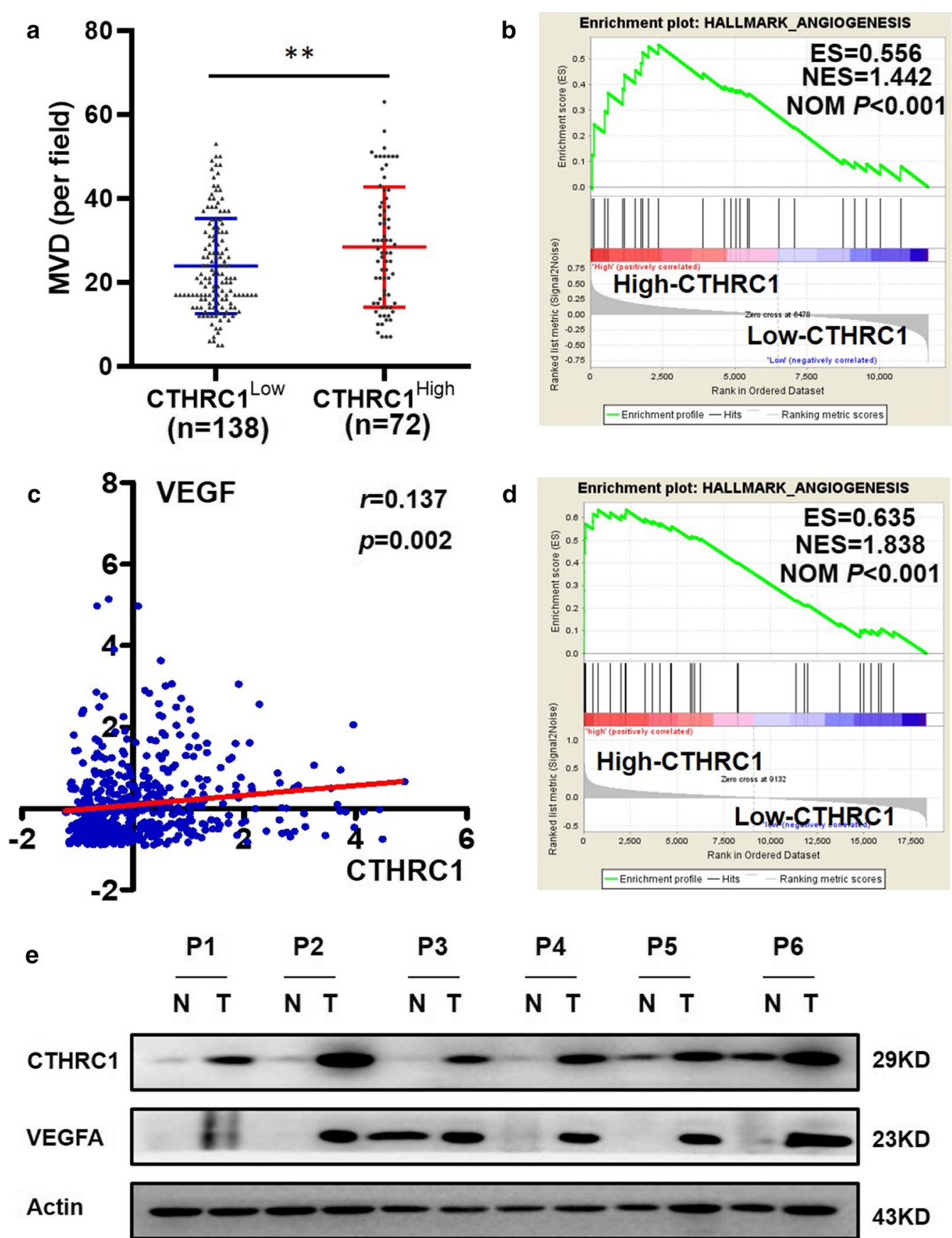

Fig. 3 CTHRC1 expression was potentially associated with tumor angiogenesis markers in LUAD. a Patients with high CTHRC1 expression had a higher MVD count (mean: 23.9 vs. 28.4; ${ }^{* *} P<0.01$ ). b GSEA for angiogenesis between the high-CTHRC1 group and the low-CTHRC1 group in LUAD. c Scatter plot showing the correlation log fold change between CTHRC1 and VEGF in TCGA patients with LUAD $(n=514 ; r=0.537, P=0.002)$. d GSEA results of angiogenesis gene sets for the high-CTHRC1 expression group in TCGA patients with LUAD. e WB analysis of CTHRC1 and VEGFA expression in each of the primary LUAD tissue ( $T$ ) and corresponding non-cancerous tissue (N). GSEA, Gene Set Enrichment Analysis; ES, enrichment score; NES, normalized enrichment score; NOM P-value, normalized P-value; TCGA, the Cancer Genome Atlas; WB, western blotting; CTHRC1, Collagen triple helix repeat containing 1; VEGFA, vascular endothelial growth factor A; LUAD, lung adenocarcinoma

squamous cell carcinoma, colorectal cancer and cervical squamous cell carcinoma [29, 38-40]. Similarly, we have previously analyzed the relationship between CTHRC1 expression and clinicopathologic features in NSCLC and found that higher CTHRC1 expression predicted poor prognosis [23]. However, large sample studies are scarce 
a

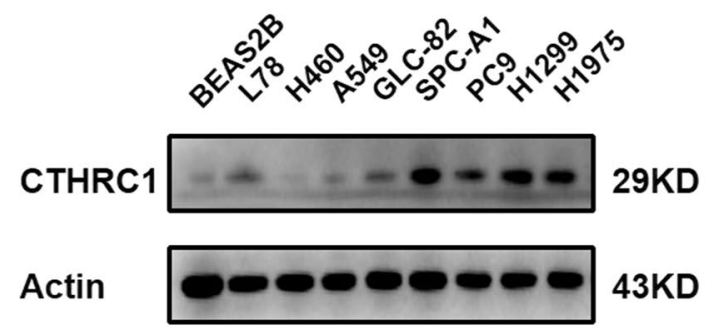

c

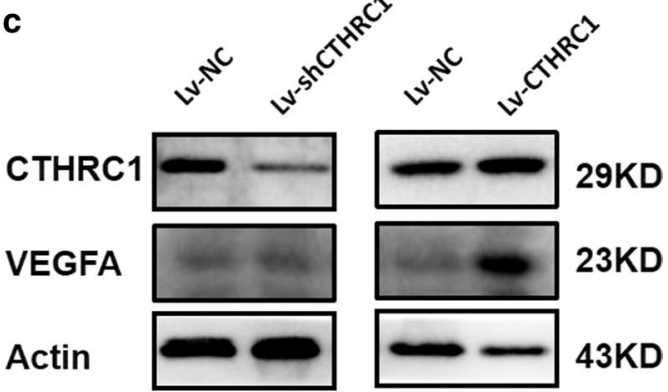

H1299

A549

b

Lv-NC

Lv-shCTHRC1

H1299
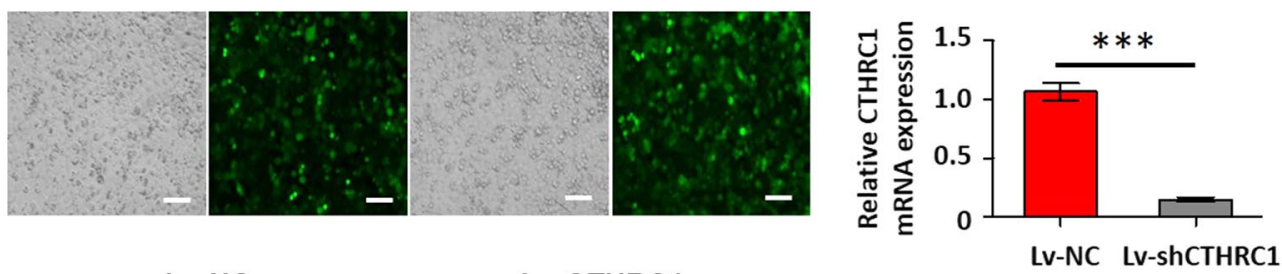

Lv-NC
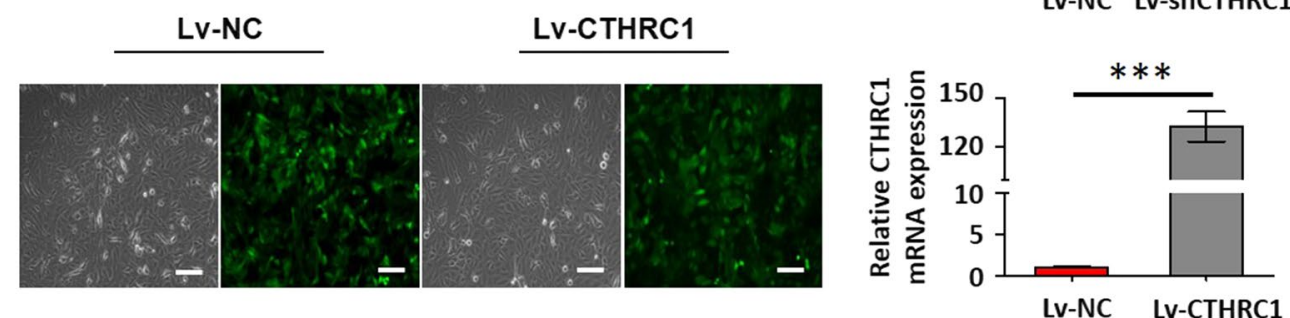

Fig. 4 Enhanced CTHRC1 expression can promote VEGF expression in LUAD in vitro. a CTHRC1 protein was detected by WB in BEAS-2B, lung non-adenocarcinoma cell lines (L78 and H460) and lung adenocarcinoma cell lines (A549, GLC-82, SPC-A1, PC9, H1299 and H1975). b GFP expression after $\mathrm{H} 1299$ and A549 transfection with the high-expressions CTHRC1 lentivirus and the shCTHRC1 lentivirus respectively. CTHRC1 mRNA expression was analyzed by using the qRT-PCR. Scale bar: 100um. Error bars represent mean \pm SD from three independent experiments $\left({ }^{* * *} P<0.001\right) . \mathbf{c} C T H R C 1$ and VEGFA protein expression was analyzed by using the WB in the constructed LV-shCTHRC1 H1299 cells and LV-CTHRC1 A549 cells. GFP, Green fluorescent protein; qRT-PCR, quantitative real-time PCR; SD, standard deviation; CTHRC1, Collagen triple helix repeat containing 1; VEGFA, vascular endothelial growth factor $A$; LUAD, lung adenocarcinoma

that focus on CTHRC1 expression and LUAD, which is the most common diagnostic subtype of lung cancer. In this study, we used a large number of clinical samples to verify the strong relationship between the CTHRC1 expression status and LUAD prognosis. Moreover, our results showed that higher CTHRC1 expression can serve as an independent predictive biomarker for poor OS and PFS in LUAD.

During tumorigenesis and development, tumor tissue is often under hypoxic and hyponutrition conditions [41]. There is also a volume of work demonstrating that under these conditions, a large number of new vessels will form due to the activation of angiogenic factors that are secreted by cancer cells, providing the oxygen and nutrients needed for tumor growth [41-43]. VEGF has been identified as the most important factor of many angiogenic factors related to tumor growth, indicating that
VEGF could be a critical target for antiangiogenic therapy [44-46]. Wei et al. [47] indicated that neoadjuvant bevacizumab (a humanized anti-vascular endothelial growth factor (anti-VEGF) monoclonal antibody) in combination with chemotherapy appeared to be effective and safe in patients with unresectable stage III LUAD. However, few investigations have studied the clinical applications of anti-VEGF therapy in large LUAD samples, probably because of the difficulty in the early diagnosis of LUAD. Thus, an effective predictive panel is urgently needed to increase the accuracy of early diagnosis and to promote the development of anti-VEGF therapy in LUAD.

CTHRC1 can be upregulated to promote tumor growth (in vitro and in vivo) by several mechanisms, such as the demethylation of the CTHRC1 promoter and canonical WNT signaling, and can be inhibited by a group of microRNAs to reduce cancer growth (in vitro and 
a

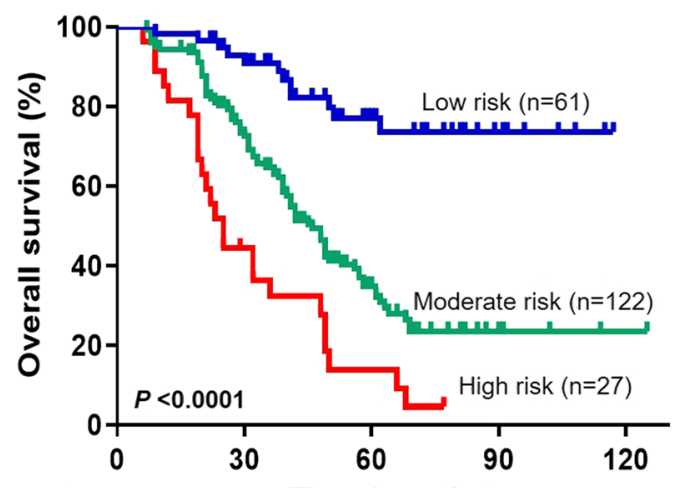

No. at risk

Low risk 61

Moderate risk 122

High risk 27

b

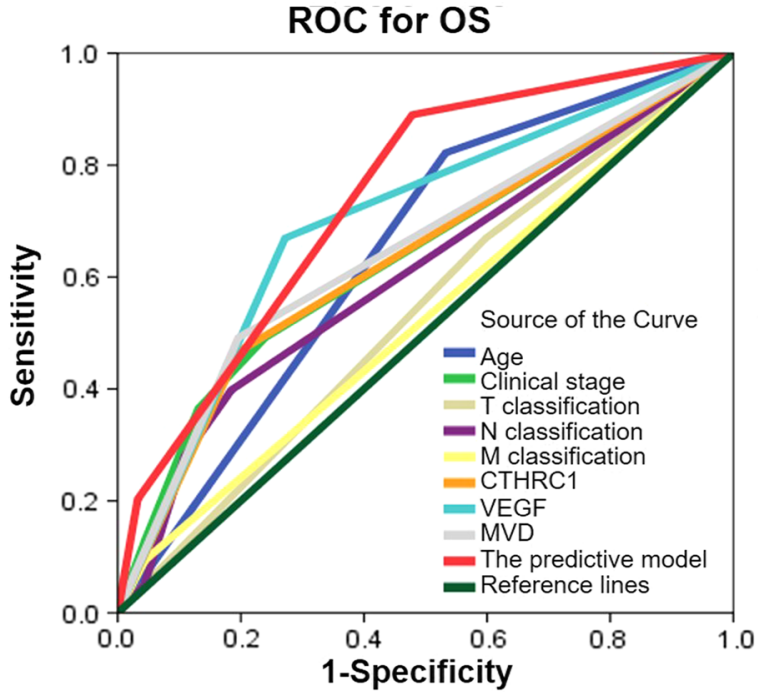

C

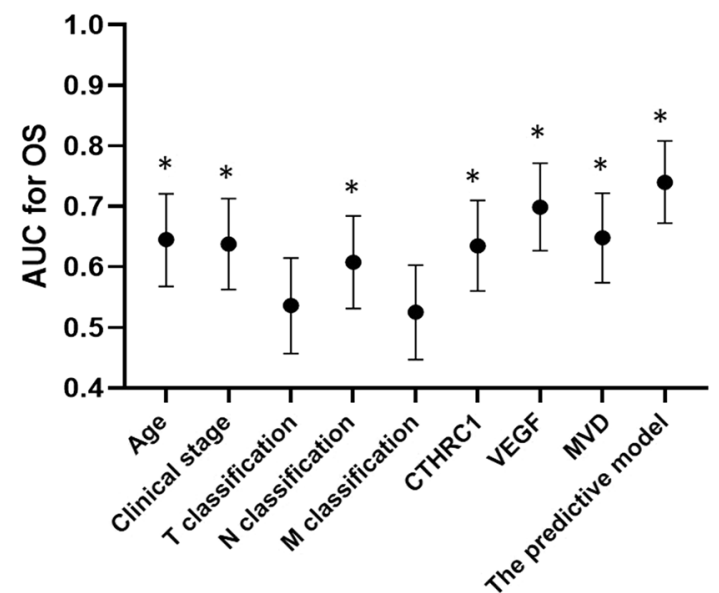

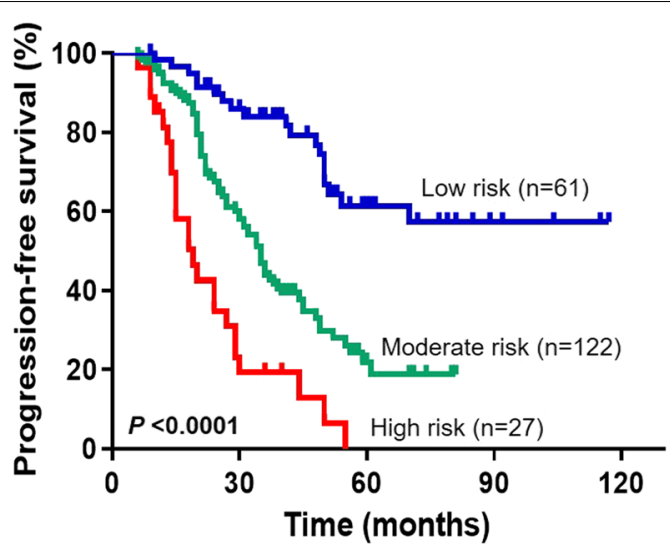

$\begin{array}{ccccc}61 & 45 & 17 & 5 & 0 \\ 122 & 58 & 7 & 0 & 0 \\ 27 & 5 & 0 & 0 & 0\end{array}$
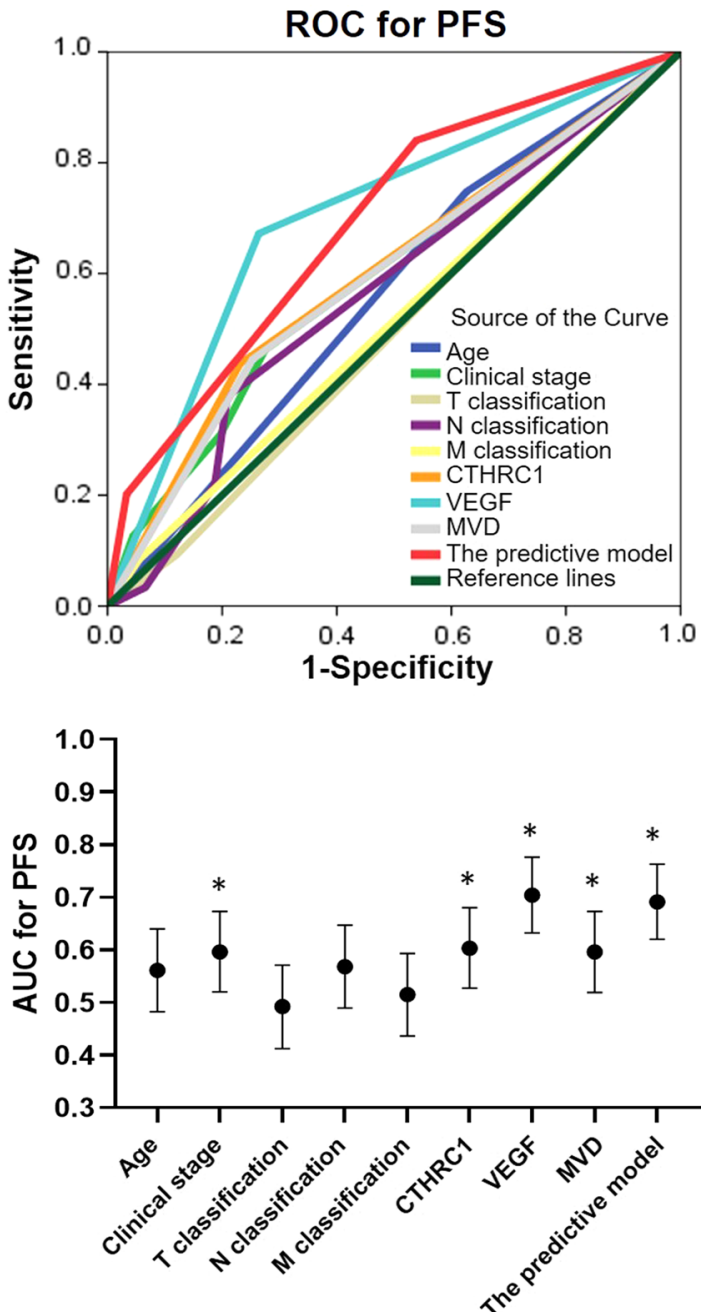

Fig. 5 Validation of the predictive model. a Kaplan-Meier analysis of OS and PFS for the predictive model in 210 LUAD patients. b The predictive ability of the predictive model compared with single markers and other clinical prognostic parameters by ROC for OS and PFS. c The AUC with the $95 \% \mathrm{Cl}$ for OS and PFS ( $\left.{ }^{*} P<0.05\right)$. The details for the AUC and $95 \% \mathrm{Cl}$ are also shown in Additional file 2: Table S5. CTHRC1, collagen triple helix repeat containing 1; VEGF, vascular endothelial growth factor; MVD, microvessel density; OS, overall survival; PFS, progression-free survival; LUAD, lung adenocarcinoma; $\mathrm{ROC}$, receiver operating characteristic; AUC, area under the curve 
Table 5 Multivariate analysis of the predictive model with clinicopathologic characteristics in LUAD patients

\begin{tabular}{|c|c|c|c|c|c|c|}
\hline \multirow[t]{2}{*}{ Variables } & \multicolumn{3}{|l|}{ OS } & \multicolumn{3}{|l|}{ PFS } \\
\hline & Hazard ratio & $95 \% \mathrm{Cl}$ & $P$-value & Hazard ratio & $95 \% \mathrm{Cl}$ & $P$-value \\
\hline Gender & 0.880 & $0.571-1.357$ & 0.564 & 1.088 & $0.713-1.662$ & 0.695 \\
\hline Age & 1.062 & $1.042-1.084$ & $<0.001$ & 1.029 & $1.010-1.049$ & 0.003 \\
\hline Smoking & 1.071 & $0.655-1.752$ & 0.784 & 0.878 & $0.541-1.427$ & 0.601 \\
\hline Tumor differentiation & 0.942 & $0.557-1.593$ & 0.823 & 1.411 & $0.869-2.289$ & 0.164 \\
\hline Clinical stage & 2.792 & $1.990-3.918$ & $<0.001$ & 3.165 & $2.236-4.480$ & $<0.001$ \\
\hline T classification & 0.840 & $0.664-1.063$ & 0.146 & 0.727 & $0.575-0.920$ & 0.008 \\
\hline N Classification & 0.935 & $0.678-1.288$ & 0.680 & 0.766 & $0.554-1.059$ & 0.107 \\
\hline M Classification & 1.633 & $0.729-3.661$ & 0.233 & 1.318 & $0.869-2.289$ & 0.517 \\
\hline The predictive model & 1.795 & $1.291-2.496$ & 0.001 & 2.301 & $1.671-3.168$ & $<0.001$ \\
\hline
\end{tabular}

$\mathrm{Cl}$ confidence interval; statistical significance $(P<0.05)$ is shown in italic

LUAD lung adenocarcinoma, OS overall survival, PFS progression-free survival, TNM tumor-node-metastasis, $\mathrm{Cl}$ Confidence interval

in vivo) in many tumors, such as gastric cancer, colorectal cancer and oral cancer [14, 18, 48-50]. However, little is known about the regulation and function of CTHRC1 in the cancer microenvironment. Recently, CTHRC1 overexpression was reported to be associated with MVD and to induce the migration and tube formation of human umbilical vein endothelial cells (HUVECs) by increasing the phosphorylation of extracellular-signal-regulated protein kinase (ERK) and c-Jun N-terminal kinase (JNK) in gastrointestinal stromal tumors [28]. The administration of a CTHRC1-neutralizing inhibitor to a xenograft mouse model reduced the tumor burden and infiltration of Tie2-expressing monocytes (TEMs) in pancreatic tumor specimens, indicating that blocking the CTHRC1/ angiopoietin-2 (Ang-2)/TEM axis during angiogenesis suppresses tumorigenesis [27]. Specifically, Zhang et al. [51] discovered that CTHRC1 activated hypoxiainducible factor $1 \alpha$ (HIF-1 $\alpha)$ and VEGF by regulating the phosphoinositide-3-kinase/protein kinase $\mathrm{B} / \mathrm{mammalian}$ target of rapamycin (PI3K/AKT/mTOR) pathway, and the knockdown of CTHRC1 resulted in the repression of hepatitis $\mathrm{B}$ virus (HBV)-associated carcinogenesis in nude mice. However, the relationship between CTHRC1 expression and tumor angiogenesis and tumor microenvironment in LUAD is still unclear. This encourages our future work to further explore the underlying mechanisms of how high CTHRC1 expression promotes angiogenesis in LUAD.

In this study, we observed that CTHRC1 expression, an independent predictor of prognosis in LUAD, was positively associated with tumor angiogenesis markers, and the GSEA data provided more evidence that gene expression related to the promotion of angiogenesis was more activated in the high-CTHRC1 group with LUAD than in the low-CTHRC1 group. Furthermore, we validated that enhanced CTHRC1 expression can promote VEGF expression in LUAD in vitro. Based on the aforementioned results, it was reasonable to combine CTHRC1 and tumor angiogenesis markers to construct a predictive model in LUAD. Additionally, we found that the constructed predictive model can be used as a more accurate prognostic panel, as it exhibited the best predictive power for OS and PFS in LUAD patients. However, the specific functional mechanism in this study remains to be studied, and we will further explore the potential mechanism between CTHRC1 expression and tumor angiogenesis in LUAD in our next study.

\section{Conclusions}

In summary, high CTHRC1 expression may be closely associated with angiogenesis, and the combination of CTHRC1 with angiogenesis markers in a predictive model can be used as a functional biomarker panel to predict prognosis in LUAD.

\section{Supplementary information}

Supplementary information accompanies this paper at https://doi. org/10.1186/s12935-019-1041-5.

Additional file 1: Figure S1. Representative immunochemistry stains for CTHRC1, VEGF and CD34. Representative image of $\mathbf{a}$ 0, b $0-10 \%, \mathbf{c}$ $11-50 \%$, d $51-75 \%$ and $\mathbf{e}>75 \%$ of cancer cells stained for CTHRC 1 IHC staining and $\mathbf{f}-\mathbf{j}$ for five cancer cells stained categories for VEGF IHC staining in LUAD tissue samples. $\mathbf{k}-\mathbf{o}$ IHC staining of different MVDs in LUAD tissue arrays. Scale bar: $50 \mu \mathrm{m}$. CTHRC1, collagen triple helix repeat containing 1; VEGF, vascular endothelial growth factor; MVD, microvessel density; IHC, immunochemistry; LUAD, lung adenocarcinoma. Figure S2. Advanced clinical stage determined the worse prognosis in LUAD. Kaplan-Meier survival curves for OS and PFS according to a clinical stage, b T, c N, and $\mathbf{d} \mathrm{M}$ classification. Vertical tick marks censored subjects. Bonferroni correction was used to adjust the statistical significance level (Table S1-3). CTHRC1, collagen triple helix repeat containing 1; VEGF, vascular endothelial growth factor; MVD, microvessel density; LUAD, lung 
adenocarcinoma; OS, overall survival; PFS, progression-free survival. Figure S3. No significant difference was observed between CTHRC1-High group and CTHRC1-Low group in $\mathbf{a}, \mathbf{b} T 3-4, \mathbf{c}, \mathbf{d} \mathrm{N} 1-3$ and $\mathbf{e}, \mathbf{f} \mathrm{M} 1$ subgroups.

Additional file 2: Table S1. Multiple comparison of OS and PFS between different clinical stages. Table S2. Multiple comparison of OS and PFS between different T classifications. Table S3. Multiple comparison of OS and PFS between different $\mathrm{N}$ classifications. Table S4. Multiple comparison of OS and PFS between different risk groups. Table S5. The ROC analyses of variables for OS and PFS.

\section{Abbreviations}

CTHRC1: collagen triple helix repeat containing 1; LUAD: lung adenocarcinoma; VEGF: vascular endothelial growth factor; MVD: microvessel density; OS: overall survival; PFS: progression-free survival; NSCLC: non-small cell lung cancer; FFPE: formalin-fixed and paraffin-embedded; IHC: immunohistochemistry; ROC: receiver operating characteristic; GSEA: gene set enrichment analysis; MSigDB: molecular signatures database; TCGA: The Cancer Genome Atlas; ES: enrichment score; NES: normalized enrichment score; NOM $P$ value: normalized $P$-value; SD: standard deviation; AUC: areas under the curve; Cl: confidence interval; PDAC: pancreatic ductal adenocarcinoma; WB: western blotting; qRT-PCR: quantitative real-time PCR; GFP: green fluorescent protein; VEGFA: vascular endothelial growth factor A; anti-VEGF: anti-vascular endothelial growth factor; HUVECs: human umbilical vein endothelial cells; ERK: extracellular-signal-regulated protein kinase; JNK: c-Jun N-terminal kinase; TEMs: Tie2-expressing monocytes; Ang-2: angiopoietin-2; HIF-1a: hypoxiainducible factor 1a; PI3K: phosphoinositide-3-kinase; AKT: protein kinase B; mTOR: mammalian target of rapamycin; $\mathrm{HBV}$ : hepatitis B virus.

\section{Acknowledgements}

I am truly grateful for the endless support and care provided by my boyfriend Red Zhu, without which this study could not have been conducted.

\section{Authors' contributions}

Conception and design: ZK, YC, CZ; funding support: ZK; collection and assembly of data: YS, YC, YL, NJ, WJ, HW, LC, JL, YC, and KT; manuscript writing: YC. All authors read and approved the final manuscript.

\section{Funding}

This work was supported by grants from YFC (2017YFC1308800), National Natural Science Foundation of China to Zunfu Ke (30900650, 81372501, $81572260,81773299,81701834,81502327,81172232$ and 31430030), and Guangdong Natural Science Foundation (2011B031800025, S2012010008378, S2012010008270, S2013010015327, 2013B021800126, 20090171120070, 9451008901002146, 2014A030313052, 2014J4100132, 2015A020214010, 2016A020215055, 201704020094, 2013B021800259, 2017B070705002, $16 y k j c 08$ and 2015ykzd07).

\section{Availability of data and materials}

All data generated or analyzed during this current study are available from the corresponding author on reasonable request.

\section{Ethics approval and consent to participate}

This study was approved by the institutional ethics committee of the First Affiliated Hospital of Sun Yat-sen University, and written informed consent was obtained from all patients.

\section{Consent for publication}

Not applicable.

\section{Competing interests}

The authors declare that they have no competing interests.

\section{Author details}

${ }^{1}$ Department of Pathology, The First Affiliated Hospital, Sun Yat-sen University, No. 58, Zhongshan Second Road, Guangzhou 510080, Guangdong, People's Republic of China. ${ }^{2}$ Department of Thoracic Surgery, The First Affiliated Hospital, Sun Yat-sen University, Guangzhou 510080, Guangdong, People's Republic of China. ${ }^{3}$ Department of Respiratory Medicine, The First Affiliated Hospital, Sun Yat-sen University, Guangzhou 510080, Guangdong, People's
Republic of China. ${ }^{4}$ State Key Laboratory of Respiratory Disease, National Clinical Research Center for Respiratory Disease, Guangzhou Institute of Respiratory Health, The First Affiliated Hospital of Guangzhou Medical University, Guangzhou 510080, Guangdong, People's Republic of China. ${ }^{5}$ Institute of Precision Medicine, The First Affiliated Hospital, Sun Yat-sen University, Guangzhou 510080, Guangdong, People's Republic of China.

Received: 15 July 2019 Accepted: 18 November 2019

Published online: 29 November 2019

\section{References}

1. Bray F, Ferlay J, Soerjomataram I, Siegel RL, Torre LA, Jemal A. Global cancer statistics 2018: GLOBOCAN estimates of incidence and mortality worldwide for 36 cancers in 185 countries. CA Cancer J Clin. 2018;68(6):394-424.

2. Siegel RL, Miller KD, Jemal A. Cancer statistics, 2017. CA Cancer J Clin. 2017;67(1):7-30.

3. Siegel R, Ward E, Brawley O, Jemal A. Cancer statistics, 2011: the impact of eliminating socioeconomic and racial disparities on premature cancer deaths. CA Cancer J Clin. 2011;61(4):212-36.

4. Herbst RS, Heymach JV, Lippman SM. Lung cancer. N Engl J Med. 2008;359(13):1367-80.

5. Hirsch FR, Scagliotti GV, Mulshine JL, Kwon R, Curran WJ Jr, Wu YL, PazAres L. Lung cancer: current therapies and new targeted treatments. Lancet. 2017;389(10066):299-311.

6. Imielinski M, Berger AH, Hammerman PS, Hernandez B, Pugh TJ, Hodis E, Cho J, Suh J, Capelletti M, Sivachenko A, et al. Mapping the hallmarks of lung adenocarcinoma with massively parallel sequencing. Cell. 2012;150(6):1107-20.

7. Choi CM, Jang SJ, Park SY, Choi YB, Jeong JH, Kim DS, Kim HK, Park KS, Nam BH, Kim HR, et al. Transglutaminase 2 as an independent prognostic marker for survival of patients with non-adenocarcinoma subtype of non-small cell lung cancer. Mol Cancer. 2011;10:119.

8. Kim HS, Park K, Jun HJ, Yi SY, Lee J, Ahn JS, Park YH, Kim S, Lee S, Ahn MJ. Comparison of survival in advanced non-small cell lung cancer patients in the pre- and post-gefitinib eras. Oncology. 2009;76(4):239-46.

9. Coate LE, Leighl NB. How affordable are targeted therapies in non-small cell lung cancer? Curr Treat Options Oncol. 2011;12(1):1-11.

10. Mahvi DA, Liu R, Grinstaff MW, Colson YL, Raut CP. Local cancer recurrence: the realities, challenges, and opportunities for new therapies. CA Cancer J Clin. 2018;68(6):488-505.

11. Sardenberg RA, Pinto C, Bueno CA, Younes RN. Non-small cell lung cancer stage IV long-term survival with isolated spleen metastasis. Ann Thorac Surg. 2013;95(4):1432-4.

12. Kelley MW. Leading Wnt down a PCP path: Cthrc1 acts as a coreceptor in the Wnt-PCP pathway. Dev Cell. 2008;15(1):7-8.

13. Stohn JP, Perreault NG, Wang Q, Liaw L, Lindner V. Cthrc1, a novel circulating hormone regulating metabolism. PLOS ONE. 2012;7(10):e47142.

14. Liu G, Sengupta PK, Jamal B, Yang HY, Bouchie MP, Lindner V, Varelas $X$, Kukuruzinska MA. N-glycosylation induces the CTHRC1 protein and drives oral cancer cell migration. J Biol Chem. 2013;288(28):20217-27.

15. Takeshita S, Fumoto T, Matsuoka K, Park KA, Aburatani H, Kato S, Ito M, Ikeda K. Osteoclast-secreted CTHRC1 in the coupling of bone resorption to formation. J Clin Invest. 2013;123(9):3914-24.

16. Ikeda K, Takeshita S. Factors and mechanisms involved in the coupling from bone resorption to formation: how osteoclasts talk to osteoblasts. J Bone Metab. 2014;21(3):163-7.

17. Pyagay P, Heroult M, Wang Q, Lehnert W, Belden J, Liaw L, Friesel RE, Lindner $V$. Collagen triple helix repeat containing 1, a novel secreted protein in injured and diseased arteries, inhibits collagen expression and promotes cell migration. Circ Res. 2005;96(2):261-8.

18. Wang P, Wang YC, Chen XY, Shen ZY, Cao H, Zhang YJ, Yu J, Zhu JD, Lu YY, Fang JY. CTHRC1 is upregulated by promoter demethylation and transforming growth factor-beta1 and may be associated with metastasis in human gastric cancer. Cancer Sci. 2012;103(7):1327-33.

19. Kim JH, Baek TH, Yim HS, Kim KH, Jeong SH, Kang HB, Oh SS, Lee HG, Kim JW, Kim KD. Collagen triple helix repeat containing-1 (CTHRC1) expression in invasive ductal carcinoma of the breast: the impact on 
prognosis and correlation to clinicopathologic features. Pathol Oncol Res. 2013;19(4):731-7.

20. Zhang G, Li G. Novel multiple markers to distinguish melanoma from dysplastic nevi. PLoS ONE. 2012;7(9):e45037.

21. Chen YL, Wang TH, Hsu HC, Yuan RH, Jeng YM. Overexpression of CTHRC1 in hepatocellular carcinoma promotes tumor invasion and predicts poor prognosis. PLoS ONE. 2013;8(7):e70324.

22. Tan F, Liu F, Liu H, Hu Y, Liu D, Li G. CTHRC1 is associated with peritoneal carcinomatosis in colorectal cancer: a new predictor for prognosis. Med Oncol. 2013;30(1):473

23. Ke Z, He W, Lai Y, Guo X, Chen S, Li S, Wang Y, Wang L. Overexpression of collagen triple helix repeat containing 1 (CTHRC1) is associated with tumour aggressiveness and poor prognosis in human non-small cell lung cancer. Oncotarget. 2014;5(19):9410-24.

24. Folkman J. Tumor angiogenesis: therapeutic implications. N Engl J Med. 1971;285(21):1182-6.

25. Abidin AZ, Garassino MC, Califano R, Harle A, Blackhall F. Targeted therapies in small cell lung cancer: a review. Ther Adv Med Oncol. 2010;2(1):25-37.

26. Popper HH. Progression and metastasis of lung cancer. Cancer Metastasis Rev. 2016;35(1):75-91.

27. Lee J, Song J, Kwon ES, Jo S, Kang MK, Kim YJ, Hwang Y, Bae H, Kang $\mathrm{TH}$, Chang $\mathrm{S}$, et al. CTHRC1 promotes angiogenesis by recruiting Tie2-expressing monocytes to pancreatic tumors. Exp Mol Med. 2016;48(9):e261.

28. Fu SW, Chen HY, Lin XL, Yang L, Ge ZZ. Collagen triple helix repeat containing 1 promotes tumor angiogenesis in gastrointestinal stromal tumors. Oncol Lett. 2017;14(6):7499-505.

29. Ni S, Ren F, Xu M, Tan C, Weng W, Huang Z, Sheng W, Huang D. CTHRC1 overexpression predicts poor survival and enhances epithelial-mesenchymal transition in colorectal cancer. Cancer Med. 2018;7(11):5643-54.

30. Kim HC, Kim YS, Oh HW, Kim K, Oh SS, Kim JT, Kim BY, Lee SJ, Choe YK, Kim $\mathrm{DH}$, et al. Collagen triple helix repeat containing 1 (CTHRC1) acts via ERKdependent induction of MMP9 to promote invasion of colorectal cancer cells. Oncotarget. 2014:5(2):519-29.

31. Cui Y, Fang W, Li C, Tang K, Zhang J, Lei Y, He W, Peng S, Kuang M, Zhang $\mathrm{H}$, et al. Development and validation of a novel signature to predict overall survival in "Driver Gene-negative" lung adenocarcinoma (LUAD): results of a multicenter study. Clin Cancer Res. 2019;25(5):1546-56.

32. He W, Zhang H, Wang Y, Zhou Y, Luo Y, Cui Y, Jiang N, Jiang W, Wang H, $\mathrm{Xu}$ D, et al. CTHRC1 induces non-small cell lung cancer (NSCLC) invasion through upregulating MMP-7/MMP-9. BMC Cancer. 2018;18(1):400.

33. Weidner N, Semple JP, Welch WR, Folkman J. Tumor angiogenesis and metastasis—correlation in invasive breast carcinoma. N Engl J Med. 1991;324(1):1-8.

34. Lee CE, Vincent-Chong VK, Ramanathan A, Kallarakkal TG, Karen-Ng LP, Ghani WM, Rahman ZA, Ismail SM, Abraham MT, Tay KK, et al. Collagen triple helix repeat containing-1 (CTHRC1) expression in oral squamous cell carcinoma (OSCC): prognostic value and clinico-pathological implications. Int J Med Sci. 2015;12(12):937-45.

35. Zlobec I, Vuong T, Hayashi S, Haegert D, Tornillo L, Terracciano L, Lugli A, Jass J. A simple and reproducible scoring system for EGFR in colorectal cancer: application to prognosis and prediction of response to preoperative brachytherapy. Br J Cancer. 2007;96(5):793-800.

36. Fleige S, Walf V, Huch S, Prgomet C, Sehm J, Pfaffl MW. Comparison of relative $m R N A$ quantification models and the impact of RNA integrity in quantitative real-time RT-PCR. Biotech Lett. 2006;28(19):1601-13.
37. Liu W, Fu XL, Yang JY, Yang MW, Tao LY, Liu DJ, Huo YM, Zhang JF, Hua R, Sun YW. Elevated expression of CTHRC1 predicts unfavorable prognosis in patients with pancreatic ductal adenocarcinoma. Am J Cancer Res. 2016;6(8):1820-7.

38. Qi C, Hu Y, Yang F, An H, Zhang J, Jin H, Guo F. Preliminary observations regarding the expression of collagen triple helix repeat-containing 1 is an independent prognostic factor for Wilms'tumor. J Pediatr Surg. 2016;51(9):1501-6.

39. Wang C, Li Z, Shao F, Yang X, Feng X, Shi S, Gao Y, He J. High expression of Collagen Triple Helix Repeat Containing 1 (CTHRC1) facilitates progression of oesophageal squamous cell carcinoma through MAPK/MEK/ERK/ FRA-1 activation. J Exp Clin Cancer Res. 2017;36(1):84.

40. Li N, Chen L, Liu C, Jiang Y, Rong J. Elevated CTHRC1 expression is an indicator for poor prognosis and lymph node metastasis in cervical squamous cell carcinoma. Hum Pathol. 2019;85:235-41.

41. Kuczynski EA, Vermeulen PB, Pezzella F, Kerbel RS, Reynolds AR. Vessel cooption in cancer. Nat Rev Clin Oncol. 2019. https://doi.org/10.1038/s4157 1-019-0181-9.

42. Altorki NK, Markowitz GJ, Gao D, Port JL, Saxena A, Stiles B, McGraw T, Mittal $V$. The lung microenvironment: an important regulator of tumour growth and metastasis. Nat Rev Cancer. 2019;19(1):9-31.

43. De Palma M, Biziato D, Petrova TV. Microenvironmental regulation of tumour angiogenesis. Nat Rev Cancer. 2017;17(8):457-74.

44. Jayson GC, Kerbel R, Ellis LM, Harris AL. Antiangiogenic therapy in oncology: current status and future directions. Lancet. 2016;388(10043):518-29.

45. Goel HL, Mercurio AM. VEGF targets the tumour cell. Nat Rev Cancer. 2013;13(12):871-82.

46. Bais C, Mueller B, Brady MF, Mannel RS, Burger RA, Wei W, Marien KM, Kockx MM, Husain A, Birrer MJ, et al. Tumor microvessel density as a potential predictive marker for bevacizumab benefit: GOG-0218 biomarker analyses. J Natl Cancer Inst. 2017. https://doi.org/10.1093/jnci/ djx066.

47. Ou W, Li N, Wang SY, Li J, Liu QW, Huang QA, Wang BX. Phase 2 trial of neoadjuvant bevacizumab plus pemetrexed and carboplatin in patients with unresectable stage III lung adenocarcinoma (GASTO 1001). Cancer. 2016;122(5):740-7.

48. Yan L, Yu J, Tan F, Ye GT, Shen ZY, Liu H, Zhang Y, Wang JF, Zhu XJ, Li GX. SP1-mediated microRNA-520d-5p suppresses tumor growth and metastasis in colorectal cancer by targeting CTHRC1. Am J Cancer Res. 2015;5(4):1447-59.

49. Yu J, Feng J, Zhi X, Tang J, Li Z, Xu Y, Yang L, Hu Z, Xu Z. Let-7b inhibits cell proliferation, migration, and invasion through targeting Cthrc 1 in gastric cancer. Tumour Biol. 2015;36(5):3221-9.

50. Taylor MA, Parvani JG, Schiemann WP. The pathophysiology of epithelialmesenchymal transition induced by transforming growth factor-beta in normal and malignant mammary epithelial cells. J Mammary Gland Biol Neoplasia. 2010;15(2):169-90

51. Zhang R, Cao Y, Bai L, Zhu C, Li R, He H, Liu Y, Wu K, Liu F, Wu J. The collagen triple helix repeat containing 1 facilitates hepatitis $B$ virus-associated hepatocellular carcinoma progression by regulating multiple cellular factors and signal cascades. Mol Carcinog. 2015;54(12):1554-66.

\section{Publisher's Note}

Springer Nature remains neutral with regard to jurisdictional claims in published maps and institutional affiliations. 